\title{
Guia de Avaliação das Capacidades Parentais: Estudo de Validade Ecológica
}

\author{
Dora Pereira ${ }^{1}$ \\ Madalena Alarcão \\ Universidade de Coimbra
}

\begin{abstract}
RESUMO - Este estudo teve como objetivo avaliar e maximizar a adequação do Guia de Avaliação das Capacidades Parentais (De Rancourt, Paquette, Paquette, \& Rainville, 2006) ao sistema de proteção à infância português. Utilizou-se uma metodologia de grupos focais com técnicos psicossociais, magistrados e académicos que trabalham diretamente com a avaliação da parentalidade. As discussões focaram a exequibilidade da aplicação, a utilidade da informação recolhida e dos juízos clínicos efetuados para a elaboração de pareceres técnicos, e as alterações consideradas necessárias. Da análise efetuada com o software QSRNVivo8, concluiu-se que o Guia assenta em conhecimento científico atualizado e possibilita a obtenção de informação suficiente. Foram identificadas e detalhadas alterações metodológicas, estruturais e de conteúdo a introduzir no instrumento.
\end{abstract}

Palavras- chave: capacidades parentais, avaliação, proteção à infância, validade ecológica

\section{Evaluation Guide of Parental capacities: An Ecological Validity Study}

\begin{abstract}
This aim of this study was to promote and improve the adaptation of the Parental Capacities Evaluation Guide (De Rancourt, Paquette, Paquette, \& Rainville, 2006) to the Portuguese child protection system. A focus group methodology was used with professionals who work directly on parenting assessment: Social workers, judges and researchers. The discussions of the focus group concentrated on the Guide 'feasibility, the usefulness of the information obtained, the clinical judgements made and on the major changes needed. From content analysis with the QSRNVivo8 software, it was concluded that the Guide is based on updated scientific knowledge and that it provides sufficient information for the assessment of parenting capacities. Three major kinds of changes to be made were identified: methodological, structural and content changes.
\end{abstract}

Keywords: parenting capacities, assessment, child protection, ecological validity

A avaliação da capacidade parental no quadro da proteção à infância implica tarefas complexas como sejam a condução da avaliação, a análise e transmissão da informação obtida e a clarificação das suas implicações para o processo de tomada de decisão sobre o futuro das relações entre crianças e prestadores de cuidados. Contudo, a falta de instrumentos validados para o contexto português prejudica a qualidade dessas avaliações, na medida em que potencia a continuidade de práticas de avaliação muito heterogéneas, sem que se diferencie claramente este de outros tipos de avaliações no que aos seus objetivos, metodologias, potencialidades e limitações diz respeito. Num contexto em que as decisões que venham a ser tomadas têm implicações a longo prazo, nomeadamente ao nível da qualidade do desenvolvimento da criança, e mesmo no que toca às gerações futuras, importa que a sua fundamentação assente em critérios validados cientificamente.

A validação ecológica do Guia de Avaliação das Capacidades Parentais constitui um primeiro passo no processo de validação deste instrumento para o contexto português. Neste artigo apresenta-se um estudo qualitativo desenvolvido com profissionais portugueses de referência, de três grupos de profissionais distintos, mas com experiência na área da proteção à infância: técnicos psicossociais, magistrados e académicos. São apresentados e discutidos

1 Endereço para correspondência: Rua General Humberto Delgado, 19, Évora, Potugal. CEP: 7005-500. E-mail: disabelp@netvisao.pt os resultados obtidos, nomeadamente ao nível das principais alterações sugeridas.

\section{A Avaliação da Capacidade Parental}

Segundo Paquette (2004), a capacidade parental comporta uma dimensão de permanência e de limite, remetendo para o potencial do prestador de cuidados, atualizado ou latente, que lhe permite exercer o seu papel. Por outras palavras, diz respeito ao que lhe é possível fazer e refere-se à estrutura que permitirá (ou dificultará) a atualização e desenvolvimento das competências parentais, o que remete para uma dimensão diacrónica. Para Barudy e Dantagnan (2010), existem quatro capacidades parentais fundamentais: a) vinculação, i.é, capacidade de se vincular aos filhos e responder às suas necessidades; b) empatia, ou seja, a capacidade de perceber as necessidades do outro e de se sintonizar com elas; c) modelos de cuidado, que incluem "as formas de perceber e compreender as necessidades das crianças e [de saber] como responder para as satisfazer, protegendo, educando e assegurando a [sua] socialização" (Barudy \& Dantagnan, 2010, p. 224); d) capacidade de participar na vida comunitária, proporcionando e recebendo apoio social.

A competência parental, pelo contrário, tem um carácter circunstancial e evolutivo e corresponde à soma das atitudes e das condutas favoráveis ao desenvolvimento normal da criança (Paquete, 2004). Dado que os fatores contextuais podem afetar de forma favorável ou desfavorável o exercício 
do papel parental, as competências podem melhorar ou deteriorar-se com o tempo. Assim, as competências parentais remetem para uma dimensão sincrónica, correspondendo aos recursos comportamentais, cognitivos e emocionais que um prestador de cuidados utiliza num determinado momento para responder às necessidades da criança (p.e., prestação de cuidados básicos, estabelecimento de regras e limites, estimulação adequada da criança, gestão do seu comportamento, promoção da sua socialização).

No entanto, os dois termos são muitas vezes usados como sinónimos, o que constitui um erro conceptual que pode inviabilizar uma correta fundamentação para a intervenção futura, como acontece no Framework for the Assessment of Children in Need and their Families (Department of Health, Department for Education and Employment \& Home Office, 2000) ou no Guia de orientações para os profissionais da ação social na abordagem de situações de maus tratos ou outras situações de perigo (Comissão Nacional de Proteção de Crianças e Jovens, 2011). No entanto, para fundamentar medidas a longo prazo, a avaliação não pode centrar-se no exame das competências parentais atuais; é necessário conhecer as capacidades parentais para que possa perspectivar-se que mudanças podem ocorrer e o que é necessário para que tal aconteça. A avaliação da capacidade parental implica a consideração da complexidade ecológica da parentalidade e não deve ser encarada como a avaliação de um traço individual (Family Disability Studies Initiative, 2012).

\section{Objetivos da Avaliação e Potencialidades para a Intervenção}

\section{Entre a avaliação forense e a avaliação clínica}

White (2005) aponta três objetivos específicos para as avaliações da capacidade parental: a) proteger as crianças dos riscos que podem sofrer no seu meio; b) decidir se estas devem ser ou não separadas dos pais; c) decidir se podem regressar ao cuidado dos pais, uma vez tendo sido retiradas. Tais objetivos, muito pertinentes para a decisão a tomar em casos de regulação das responsabilidades parentais em situações de disputa familiar ou de destituição do poder parental, espelham que a avaliação se situa no cruzamento do conhecimento, do julgamento e da decisão (Bernoux, citado por Robin, 2011), implicando sempre um ato relacional.

No contexto da proteção à infância, as avaliações da capacidade e competências parentais situam-se numa zona de interseção entre a área forense e a área clínica, exigindo uma cuidada gestão da relação entre o/s avaliador/es e o/s prestador/es de cuidados, que assegure a compreensão, por parte deste último, do processo de avaliação e das suas implicações. Steinhauer (1993) considera que as avaliações devem responder a duas questões essenciais: i) saber se a forma como é exercida a parentalidade cumpre os padrões mínimos compatíveis com um desenvolvimento normal, e ii) saber qual é a probabilidade de a parentalidade melhorar em função da intervenção. Centrando-se na questão da relação entre as necessidades específicas da criança e as competências do prestador de cuidados (goodness of fit),
Bowden (2009) refere que o objetivo central da avaliação é a identificação das forças e fraquezas de um determinado prestador de cuidados relativamente a uma determinada criança. Barudy e Dantagnan (2010) consideram que tais avaliações devem responder às seguintes questões: a) quais são as competências parentais atuais; b) quais são as possibilidades de modificar essas competências; c) o que fazer quando essas competências parecem irrecuperáveis; d) qual é o dano atual visível da criança; e) qual é o nível de dano em termos de possíveis transtornos de desenvolvimento (dano invisível); f) qual é a patologia social da família, como se integra nas redes sociais.

Resumindo, e partindo da tipologia de Tippins e Wittmann (2005) relativa aos níveis de inferência clínica, há quatro níveis de questões às quais é importante dar resposta: a) $\mathrm{O}$ que é que o avaliador observou durante os momentos de avaliação? b) o que é que o avaliador conclui acerca do funcionamento dos pais e da criança? c) O que é que o avaliador conclui acerca das implicações da permanência da criança junto dos pais e quais as possibilidades de mudança? d) que conclusões prescritivas o avaliador deve elaborar acerca dos contactos entre os pais e a criança?

\section{Aquém e além do risco}

A avaliação do risco e a avaliação da capacidade parental surgem referenciados na literatura como estando intrinsecamente ligadas. A avaliação do risco analisa a probabilidade do desenvolvimento da criança vir a ser prejudicado e a probabilidade de ocorrência futura de alguma forma de mau trato (Munro, 2008). A avaliação da capacidade parental pretende conhecer a forma como o papel parental é exercido agora e como poderá ser no futuro, através da caracterização das capacidades parentais, das competências parentais atuais e da possibilidade de evolução das mesmas. A avaliação do risco tende a ser utilizada na altura da sinalização, e como suporte a decisões relacionadas com a priorização do caso, o nível de gravidade do mesmo e as medidas de proteção imediata; a avaliação da capacidade parental tende a ser usada nos momentos de ponderação das estratégias de intervenção com a família e de definição do projeto de vida da criança (White, 2005).

Acresce ainda que tais avaliações utilizam instrumentos diferentes: na avaliação do risco muito se tem debatido sobre o uso de métodos atuariais, nos quais se identifica a presença de fatores de risco significativamente relacionados com a ocorrência de mau trato e se definem pontos de corte quantitativos, e a utilização dos métodos clínicos, que implicam uma leitura da dinâmica existente entre os fatores de risco identificados, sem depender de uma interpretação linear da pontuação obtida (Munro, 2008). Na avaliação da capacidade parental são utilizados sobretudo instrumentos de juízo clínico (Choate \& Engstrom, 2014), na sua maioria sob a forma de guias de avaliação (como o que nos propomos validar), que implicarão uma leitura compreensiva da informação obtida. Contudo, ainda que o risco e a capacidade parental apareçam como fatores integrados em cada um dos tipos de avaliação, é importante perceber que uma não 
equivale à outra, e que ambas são necessárias em pontos diferentes dos processos de intervenção.

\section{Limites atuais das avaliações}

Da literatura consultada e da nossa experiência no contexto português de proteção à infância, constata-se, com regularidade, a presença das seguintes limitações nas avaliações da capacidade parental:

a) O objetivo das avaliações da capacidade parental não está claramente delimitado e diferenciado de outro tipo de avaliações: é frequente que as mesmas sejam equiparadas a avaliações da situação social dos prestadores de cuidados, ou da personalidade. Embora os dois aspetos devam integrar a avaliação da capacidade parental, não é científica e eticamente correto inferir dos seus resultados conclusões acerca da forma como é ou pode ser exercida a parentalidade.

b) Indefinição do que constitui capacidade parental: por se entender a capacidade parental como um traço do funcionamento psicológico do prestador de cuidados, e não como uma estrutura ecologicamente complexa, é frequente encontrar processos de avaliação nos quais não houve observação de interações, ou do contexto, contactos com os membros da família, ou dados relativos à criança.

c) Utilização de medidas indiretas de avaliação cognitiva ou da personalidade para avaliar a capacidade parental, apesar de tais instrumentos não terem sido concebidos nem testados para avaliar a adequação da parentalidade.

d) Inexistência de critérios de decisão claros acerca do que poderão ser indicadores de parentalidade minimamente adequada, ficando esse juízo na dependência direta dos valores e percursos pessoais e profissionais dos avaliadores.

e) Relato descritivo da informação obtida: as conclusões das avaliações reportam às informações recolhidas ( $1^{\circ}$ nível de inferência de Tippins \& Wittmann, 2005), mas não as conceitualizam clinicamente, deixando que esta tarefa seja muitas vezes desenvolvida à luz do senso comum, por agentes do sistema de proteção sem formação adequada.

f) Inexistência de prognóstico de mudança fundamentado: é frequente não surgir qualquer prognóstico sobre a evolução dos prestadores de cuidados, sendo o futuro da criança equacionado apenas em função do risco atual, levando, por vezes, a rupturas familiares desnecessárias e prejudiciais à criança, ou, pelo contrário, ao adiamento de tais decisões em função de uma possível evolução positiva que não é validamente avaliada.

O Guia que se apresenta no ponto seguinte pretende ser um instrumento que sirva para ultrapassar essas limitações, integrando metodologias multi-sujeito e multi-método e promovendo a recolha de informação num conjunto de dimensões que, ao ser lida à luz dos pressupostos do modelo de avaliação escolhido, reflita uma formulação clinicamente compreensiva; tal deve traduzir-se nos três níveis mais elevados de inferência clínica propostos por Tippins e Wittmann (2005), construindo-se juízos clínicos cientificamente fundamentados acerca da capacidade parental, capazes de sustentar os processos de tomada de decisão em matéria de promoção e proteção à infância.

\section{O Guia}

O Guia de Avaliação das Capacidades Parentais é um instrumento de juízo clínico para auxiliar o processo de tomada de decisão. A sua utilização implica o trabalho prévio de recolha de informação através de diversos momentos, sujeitos e métodos. Ou seja, requer-se que sejam desenvolvidos, em diferentes ocasiões: a) entrevistas com os prestadores de cuidados e outros membros da família, b) observação de interações entre os mesmos e a criança, c) contactos com outros serviços envolvidos e d) visitas domiciliárias. A informação recolhida é registada sob a forma de resposta às questões colocadas pelo Guia, de forma a constituir um todo consistente, passível de leitura e análise subsequente. Tem, por isso, em conta a posição reflexiva do avaliador (Robin, 2011). Como diz Rorty (citado por Çakir, 2012), as observações dependem de vários esquemas teóricos e culturais que o observador traz para a situação. Ou seja, tratando-se de um instrumento que depende da capacidade e competências de avaliação e análise do técnico, não se enquadra na atual ideologia tecnocrática referida por Spratt e Houston (citado por Gillingham \& Humphreys, 2010) em que os instrumentos substituem o principal instrumento de trabalho dos profissionais das ciências humanas, ou seja, a relação interpessoal. A avaliação não é concebida como unilateral, apenas assente na análise da evolução das atitudes parentais e do desenvolvimento da criança, mas bilateral (Robin, 2011), dado que o Guia inclui também questões que avaliam a percepção dos pais sobre a qualidade das ajudas anteriormente recebidas.

\section{Porquê este Instrumento?}

O Guia de Avaliação das Capacidades Parentais decorre das adaptações efetuadas pelos técnicos dos Centre Jeunesse de Montréal (De Rancourt, Paquette, Paquette, \& Rainville, 2006) ao instrumento proposto em 1993 pela equipa de Paul Steinhauer, o Toronto Parenting Assessment Project. Para além do Canadá, também noutros países o instrumento de Steinhauer tem servido de base a processos semelhantes ao que ora se descreve, como é o caso de Espanha (Barudy \& Dantagnan, 2010), Suiça (Service de Protection de la Jeunesse, 2008) e França (Robin, 2011). Desde 2001 que a primeira autora e a equipa da Associação "Chão dos Meninos" vem ensaiando a sua utilização no contexto português, tendo sido identificadas diversas vantagens, nomeadamente a uniformização dos padrões de análise e a maior objetividade e fundamentação das diferentes medidas de promoção e proteção propostas. Além disso, tem permitido a diferenciação das estratégias de intervenção, inclusive ao nível das próprias dinâmicas institucionais, na medida em que, por exemplo, a sua aplicação em contextos de acolhimento exige uma maior abertura institucional (em termos de tempos e espaços) à presença dos prestadores de cuidados. 


\section{Estrutura do Guia}

O Guia de Avaliação das Capacidades Parentais (De Rancourt et al., 2006) é composto por nove dimensões de avaliação, divididas em quatro áreas (Tabela 1).

No final de cada dimensão existe um conjunto de questões resumo que incidem sobre as implicações da informação operacionalizada e analisada a partir das respostas à seguinte questão: Como é que a estrutura e conteúdos do Guia de Avaliação das Capacidades Parentais podem ser alterados de forma a atingir a sua máxima adaptação e utilidade para o contexto português? Sendo o Guia um instrumento de origem canadiana, estamos perante um processo de adaptação. Usando como referência o modelo de sensitividade cultural

Tabela 1. Áreas e dimensões de avaliação do Guia de Avaliação das Capacidades Parentais(De Rancourt et al., 2006)

\begin{tabular}{ll}
\hline \multicolumn{1}{c}{ Áreas de avaliação } & \multicolumn{1}{c}{ Dimensões de avaliação } \\
\hline Contexto & 1 - O contexto sociofamiliar \\
Saúde e desenvolvimento da criança & 2- A saúde e o desenvolvimento da criança \\
Relação criança - prestadores de cuidados & 3 - A vinculação \\
& 4 - As competências parentais \\
Prestadores de Cuidados & 5- O controlo dos impulsos \\
& 6- O reconhecimento da responsabilidade pelo prestador de \\
& cuidados \\
& 7- Os comportamentos do adulto que afetam a competência \\
& parental \\
& 8- A rede social \\
9- A história dos serviços clínicos
\end{tabular}

recolhida para o exercício da parentalidade e que permite o registro das conclusões do técnico relativamente à dinâmica específica de cada caso. Cada dimensão avaliada é classificada em uma de quatro categorias: força major, força minor, preocupação major ou preocupação minor. Tais classificações conduzem, no final do preenchimento do Guia, a um perfil da capacidade parental, o que permite a rápida identificação das dimensões que poderão vir a ser focadas no processo de intervenção. Por último, o Guia contém ainda uma escala de prognóstico de mudança, na qual é solicitado ao técnico que assinale um conjunto de características que corresponderão a uma de duas hipóteses de evolução: (A) Potencial de mudança encorajador ou (B) Alto risco de cronicidade.

\section{Validade Ecológica}

A validade ecológica tem sido enfatizada na investigação empírica e aplicada em diversas áreas da psicologia, nomeadamente no âmbito do juízo clínico e da tomada de decisão (Koehler, citado por Kvavilashvili \& Ellis, 2004). A validade ecológica deve distinguir-se da representatividade do design de investigação. Vários autores têm referido que o termo validade ecológica é muitas vezes utilizado erradamente enquanto sinónimo de validade externa/ generalização dos resultados (Araújo, Davids, \& Passos, 2007; Hammond, 1998; Schmuckler, 2001). O estudo que se apresenta utilizou um design relevante em termos ecológicos, razão pela qual se convocaram profissionais das diferentes áreas que contactam com instrumentos de avaliação da parentalidade na sua prática diária: académicos, técnicos psicossociais e magistrados.

A validade ecológica remete para a relação entre a forma de avaliar e o objeto avaliado e, no presente estudo, foi de Rossello e Bernal (1996), é importante que seja avaliada a proximidade do Guia ao contexto português em termos dos seus objetivos, contextos e agentes de aplicação, linguagem utilizada e conteúdos abordados. O objetivo essencial é perceber como é que o próprio instrumento pode ser modificado (ou mantido) de forma a poder afirmar-se que o mesmo é adequado ao contexto em estudo.

\section{Método}

\section{Participantes}

A amostra do estudo é constituída por 10 elementos de três grupos profissionais que operacionalizam o processo de avaliação da capacidade parental nos seus diferentes momentos: concepção dos instrumentos de avaliação (académicos), utilização dos mesmos (técnicos psicossociais) e tomada de decisões relacionadas com o futuro das crianças e suas famílias (magistrados). Os académicos $(n=3)$ são considerados especialistas na área da avaliação psicológica e das respostas institucionais para situações de crianças em risco ou perigo; os técnicos da área psicossocial $(n=3)$ têm mais de 15 anos de experiência na avaliação de situações de crianças em risco ou perigo, sinalizadas a comissões de proteção ou acolhidas em centros de acolhimento; os magistrados $(n=4)$ têm também larga experiência em processos judiciais de promoção e proteção e na própria formação de magistrados. Participaram, neste estudo, profissionais do sexo feminino ( $n=6)$ e masculino $(n=4)$, sendo que o grupo de académicos não incluiu profissionais do sexo masculino. 


\section{Procedimentos}

\section{Material disponibilizado e guião da discussão nos grupos focais}

Neste estudo, de natureza qualitativa, recorreu-se à constituição de três grupos focais, homogéneos quanto à área profissional. Após disponibilização e consentimento para utilização do instrumento da parte dos autores canadianos, e consentimento informado por parte dos participantes (tendo-lhes sido explicados o objetivo da investigação e os procedimentos a usar para recolha, tratamento e divulgação dos resultados), foram-lhes (previamente) remetidos quatro documentos: 1) uma apresentação enquadradora do instrumento, na qual foram abordados os seguintes pontos: a) conceitos de competência e capacidade parental; b) modelo dos determinantes do comportamento parental de Belsky e Vondra (1989) e c) breve apresentação do Guia de Avaliação das Capacidades Parentais: objetivos, forma de preenchimento (fontes de informação, tipo de registo, síntese das forças e vulnerabilidades e respetiva valoração), estrutura e conteúdos; 2) o Guia de Avaliação das Capacidades Parentais, preenchido para um caso exemplo; 3) um relatório (exemplificador do que poderia ser remetido para Tribunal para fundamentar a revisão de uma medida de promoção e proteção), construído a partir dos dados obtidos no caso exemplo referido no ponto anterior; 4) as questões que seriam posteriormente discutidas no grupo focal a que o participante pertencia.

As discussões dos vários grupos focais foram registadas em áudio e vídeo e tiveram a duração de aproximadamente $2 \mathrm{~h} 30 \mathrm{~min}$. As questões propostas encontram-se sintetizadas na Tabela 2. O primeiro conjunto de questões (Q1) foi colocado aos três grupos, o segundo conjunto de questões (Q2) foi adequado às especificidades de cada grupo profissional, incindindo sobre aspetos diretamente relacionados com a ação específica dos mesmos no âmbito da avaliação da parentalidade.

\section{Tratamento dos dados}

Após a transcrição dos registros áudios, os textos foram objeto de análise de conteúdo, tendo sido utilizado o software QSRnVivo8. Foi escolhido o tema como unidade de análise. Assim, a $1^{\mathrm{a}}$ autora fez uma primeira leitura integral das transcrições e identificou os diferentes temas abordados, criando um conjunto de categorias e subcategorias que discutiu com a $2^{\mathrm{a}}$ autora. As categorias de conteúdo não foram definidas a priori, antes decorreram da revisão sucessiva das referências numa perspetiva indutiva, guiada pelos dados, seguindo uma abordagem concordante com a grounded theory. As subcategorias constituem propriedades das categorias, tendo as referências sido agrupadas seguindo um critério de dimensionalização (LaRossa, 2005).

Posteriormente, a consistência das mesmas foi testada propondo a sua aplicação a dois codificadores, para além da primeira autora, num total de três juízes. Nas respostas do grupo focal dos magistrados, os juízes codificaram o grupo de questões Q1 (50 referências de um total de 160); no grupo focal dos técnicos codificaram a questão Q2 (46 referências de um total de 86 codificadas), após um primeiro teste-piloto em que os três juízes aplicaram e discutiram a codificação de 15 referências de ambos os grupos focais referidos. O acordo intercodificadores (Lombard, Snyder-Duch, \& Bracken, 2010), calculado ao nível das subcategorias, resultou num valor K de Fleiss de 0,96, para a questão Q1 no grupo focal dos magistrados, e de 0,90 para a questão Q2 no grupo focal dos técnicos, o que é considerado muito adequado. Esses valores foram obtidos através da folha de cálculo desenvolvida por Jason King (2004) especificamente para o cálculo de acordo entre mais de dois codificadores.

Tabela 2. Questões efetuadas aos Grupos Focais

GF1 - Técnicos GF2 - Magistrados GF3 - Académicos

Utilidade da informação recolhida e juízos clínicos efetuados para a elaboração de pareceres técnicos Os conteúdos que o Guia de Avaliação das Capacidades Parentais integra são úteis e suficientes para a produção de informação (pareceres técnicos) respeitante à avaliação da parentalidade e planificação da intervenção / das medidas a tomar?

Q1 Adequação ao sistema de promoção e proteção português

Julgariam pertinente acrescentar/retirar algum conteúdo, de forma a torná-lo mais adequado à realidade portuguesa/sistema de promoção e proteção português? Quais e porquê?

Que implicações tal teria para a ponderação da informação em termos de pontos fortes/fracos?

Exequibilidade da aplicação do Guia Utilidade dos pareceres produzidos a As tarefas solicitadas para a recolha da informação são exequíveis e adequadas?

Q2

\section{partir}

da informação recolhida para o sistema judicial

A informação produzida é útil ao sistema judicial?

Da informação produzida qual é a mais e menos útil para que um Juiz/ magistrado do MP possa decidir relativamente à manutenção da criança junto dos pais ou pela substituição definitiva dos principais prestadores de cuidados (adoção)?
Atualidade científica do Guia $O$ Guia reflete adequadamente o estado do conhecimento científico atual sobre a parentalidade e assuas implicações desenvolvimentais? 


\section{Resultados}

A Tabela 3 mostra as categorias de conteúdo nas quais foram codificadas as respostas às questões e à distribuição das codificações pelas mesmas. De seguida apresenta-se a análise das respostas com exemplos das referências codificadas.

\section{Adequação ao Sistema de Promoção e Proteção Português e Utilidade da Informação Recolhida para a Elaboração de Pareceres Técnicos}

$\mathrm{Na}$ resposta ao primeiro conjunto de questões, os participantes dos vários grupos focais consideraram que $o$
Guia é um instrumento que cobre exaustivamente as áreas de conteúdo consideradas pertinentes para a avaliação da capacidade parental e que os seus conteúdos são suficientes para a avaliação da mesma (Tabela 4, exemplos 1 e 2). Como salientaram os académicos (Tabela 4, exemplo 3) e os técnicos, o Guia ajudará a garantir a fiabilidade da avaliação, uma vez que sistematiza a informação recolhida e permite a construção de uma fundamentação mais objetiva e rigorosa, assente não na "sensibilidade" individual do técnico, mas antes num conjunto de informações e juízos clínicos relevantes para a tomada de decisão relativa às áreas em avaliação.

Tabela 3. Frequências das referências por categorias de conteúdo: validade ecológica do Guia de Avaliação das CapacidadesParentais

\begin{tabular}{|c|c|c|c|c|c|}
\hline \multirow{36}{*}{ 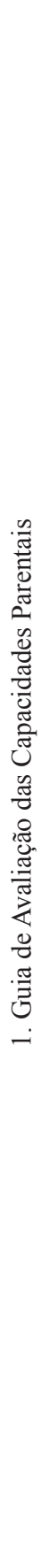 } & Categorias de conteúdo & FG1 & FG2 & FG3 & $\mathbf{T}$ \\
\hline & 1.1 Questões dos participantes & 2 & 2 & 4 & 8 \\
\hline & 1.2 Utilidade do Guia & 14 & 3 & 4 & 21 \\
\hline & 1.2.a Para a intervenção técnica & 12 & 0 & 2 & 14 \\
\hline & 1.2.b Para a produção de informação & 1 & 1 & 3 & 5 \\
\hline & 1.3 Apreciação geral do Guia & 30 & 11 & 18 & 59 \\
\hline & 1.3.a Adequação ao contexto português & 3 & 1 & 0 & 4 \\
\hline & 1.3.b Aspeto inovador & 2 & 0 & 0 & 2 \\
\hline & 1.3.c Garantia da fiabilidade da avaliação & 7 & 0 & 1 & 8 \\
\hline & 1.3.d Dimensão do instrumento & 4 & 1 & 0 & 5 \\
\hline & 1.3.e Classificação do instrumento & 0 & 0 & 1 & 1 \\
\hline & 1.3.f Atualidade e pertinência dos conteúdos & 6 & 1 & 15 & 22 \\
\hline & 1.3.g Suficiência dos conteúdos & 11 & 7 & 1 & 19 \\
\hline & 1.4 Exequibilidade da utilização & 10 & 5 & 0 & 15 \\
\hline & 1.4.a Necessidade de formação & 2 & 5 & 0 & 7 \\
\hline & 1.4.b Sistematização da informação recolhida & 1 & 0 & 0 & 1 \\
\hline & 1.4.c Aplicação faseada & 4 & 0 & 0 & 4 \\
\hline & 1.5 Lacunas & 13 & 0 & 21 & 34 \\
\hline & 1.5.a Condições de aplicação & 5 & 0 & 1 & 6 \\
\hline & 1.5.b Conteúdos não abordados & 2 & 0 & 8 & 10 \\
\hline & 1.5.c Critérios de análise da informação & 1 & 0 & 12 & 13 \\
\hline & 1.5.d Pistas para aprofundamento da avaliação & 5 & 0 & 1 & 6 \\
\hline & 1.6 Sugestões de alteração & 28 & 23 & 41 & 92 \\
\hline & 1.6.a Condições de alteração do Guia & 4 & 0 & 0 & 4 \\
\hline & 1.6.b Alterações estruturais & 6 & 0 & 0 & 6 \\
\hline & 1.6.c Alterações de conteúdo & 14 & 3 & 20 & 37 \\
\hline & 1.6.c.1 Definição dos critérios decisão & 3 & 0 & 14 & 17 \\
\hline & 1.6.c.2 Designações & 9 & 2 & 0 & 11 \\
\hline & 1.6.c.3 Dimensão de futuro & 0 & 0 & 3 & 3 \\
\hline & 1.6.c.4 Identificação de forças & 2 & 0 & 2 & 4 \\
\hline & 1.6.c.5 Terminologia & 0 & 1 & 0 & 1 \\
\hline & 1.6.d Alterações metodologia de utilização & 6 & 17 & 21 & 44 \\
\hline & 1.6.d.1 Abrangência da subescala 9 & 0 & 2 & 0 & 2 \\
\hline & 1.6.d.2 Definição de pesos relativos das dimensões & 0 & 0 & 22 & 22 \\
\hline & 1.6.d.3 Condições de utilização & 4 & 0 & 0 & 4 \\
\hline & 1.6.d.4 Proporcionalidade da utilização & 0 & 14 & 0 & 14 \\
\hline
\end{tabular}


Tabela 4. Referências exemplificativas

Exemplo 1: GF Técnicos - "T1:aquilo que eu me pareceu é que era um instrumento bastante exaustivo, (...), portanto vai ao pormenor nalgumas das situações, (...), no fundo isto o que nos vai dar é em termos de pistas de trabalho, o que é que eu posso fazer, ou seja é dizer que esta família está aqui, mas que eu daqui para a frente em termos da sua mudança o que pistas é que eu tenho, o que vou melhorar, isso para os técnicos será fundamental."

Exemplo 2: GF Magistrados - "M4:parece-me extremamente completo e que bom seria que os tribunais tivessem esta muleta de apoio".

Exemplo 3: GF Académicos - "A1:ajuda a sistematizar, ajuda também a objetivar algumas coisas e portanto a pessoa não cair só no (...) olhamos e fazemos um (...)relatório. Portanto, acho que é um instrumento muito, bom, (...) para aquilo que se propõe. Ah, que falte aqui, alguma dimensão em particular, não!"

Exemplo 4: GF Técnicos - "T3: acho que há uma sequência ao longo do instrumento, dos aspetos desde logo da vinculação, das possibilidades de(...) avaliação do risco que eu acho muito muito importante no âmbito da prevenção quer seja primária, quer seja secundária, ou terciária."

Exemplo 5: GF Académicos - "Al:é obvio que (...) eu olho pra aqui e imagino que, de facto, uma, preocupação major e uma preocupação, minor, e, e, eu quero saber é, quais são os critérios, que me levam a. (...) Porque esse, isso não está, esclarecido."

Exemplo 6: GF Técnicos - "T2:(...)há muitos momentos do instrumento que não fala das forças, há muitos momentos em que ele diz problema problema , problema, problema, (...) e só de vez em quando é que ele tem umas janelinhas abertas para as competências, para as forças."

Exemplo 7: GF Magistrados - "M4:(...) em termos de terminologias, porquê a preocupação major e minor? Vão manter isso assim? É obrigatório? (...) Não soa bem, eu de repente pensei que estava numa página em castelhano, portanto seria uma preocupação menor, maior média enfim, adaptarmos isto ao português corrente sem estarmos hipotecados (...) esse léxico que me parece não fazer grande sentido, poderá fazer para o Steinhauer mas aqui na nossa realidade não fará grande sentido."

Exemplo 8: GF Técnicos - "T3:(...)gostaria mais de às vezes ele[Guia] ter uma arrumação mais saudável nesse sentido, não é, mais de procurar as forças, ir vendo as soluções, possiveis, e fazendo esse caminho, de suporte com o próprio processo de mudança que se pede àquelas pessoas."

Exemplo 9: GF Técnicos: "T3: (...)gostava que ele ao princípio tivesse toda essa clarificação, das condições em que ele pode ser aplicado, acho que lucrávamos com isso"

Exemplo 10: GF Académicos - “A2: E estamos a considerar que todos os domínios são igualmente, importantes? A1: Não, eu não. Por isso mesmo é que eu acho que primeiro tem que atribuir pesos. A3: Todos estes, todas estes nove, nove domínios? Pois. A2: Sim, sim.."

Exemplo 11: GF Magistrados - "M1:certo, há aqui... também dependerá do caso, do caso a avaliar, quer dizer não, na maior parte das situações de perigo que nós temos, na maior parte não é, nos tribunais, ahh..., não precisa deste olhar pericial, precisa de alguns olhares periciais que aqui estão não é, e portanto não sei se, eventualmente a ser aprovado um modelo destes se ele não devia, não devia ser seccionado consoante as situações (...) porque num ou noutro caso, pode ir além do que seria do que seria absolutamente necessário."

Exemplo 12: GF Técnicos: "T1: com técnicos treinados, porque é preciso que o técnico se mexa muito bem dentro do instrumento, que o conheça ...T3: é, é...T1: para não ser redundante nalguns, nalgumas questões, (...) e poder observar por algumas respostas outras."

Exemplo 13: GF Magistrados: "M1:parece-me extremamente completo e que bom seria que os tribunais tivessem esta muleta de apoio para que pudessem de facto chegar ao momento final e dizer aqui temos um relatório que é naturalístico em termos de factos mas que também opina."

Exemplo 14: GF Magistrados: "M2: (...) este conteúdo todo que está aqui é extraordinariamente importante, se nos der para além deste os factos ....M1: em que assentam essas vossas convicções M2: em que assentam ... é ótimo."

Exemplo 15: GF Académicos: "A1:Relativamente ao resto, reflete adequadamente o estado de conhecimento cientifico? Ah, sim. (...) São estas dimensões que estão nas várias escalas.”

O Guia foi considerado útil para duas áreas fundamentais, a intervenção técnica e a produção de informação. Quanto à intervenção técnica, foi destacada a utilidade do instrumento para a intervenção preventiva (Tabela 4, exemplo 4), uma vez que permite a identificação de fatores de risco e de proteção que poderão (e deverão) ser tidos em conta na planificação da intervenção. No que toca à intervenção remediativa foi referido que o Guia poderá ser útil para aspetos como a avaliação da motivação para a mudança, a planificação da intervenção, a intervenção direcionada para o desenvolvimento das competências parentais e mesmo para a intervenção com as crianças. Tal diversidade aponta para um potencial técnico do Guia bastante abrangente.

No que respeita às lacunas do Guia foram apontados dois aspetos que estão relacionados com as sugestões de alteração propostas pelos participantes. A lacuna mais apontada ao Guia foi a de o mesmo não conter a especificação dos critérios que deverão estar subjacentes à classificação de cada subescala como área de recurso ou de dificuldade (Tabela 4, exemplo 5). A outra lacuna refere-se a conteúdos não abordados. Os 
técnicos e os académicos referiram que o instrumento estava muito centrado na identificação de aspectos problemáticos da parentalidade e não permitia a identificação de forças a não ser por defeito, ou seja, por ausência de problemas (Tabela 4, exemplo 6). Ainda que com menor frequência, foi também referido que o instrumento não contém a descrição das condições em que deve ser aplicado, nem pistas para aprofundamento da avaliação. Essas lacunas espelharamse em diversas sugestões feitas pelos participantes de modo a aumentar a validade ecológica do instrumento. Foram apontadas três ordens de sugestões: de conteúdo, estruturais e metodológicas. As alterações de conteúdo remetem para a definição dos critérios de decisão relativos à classificação das dimensões do Guia; foi também sugerido que fosse alterada a designação dessas categorias de classificação (Tabela 4, exemplo 7), uma vez que as adotadas (força major e minor, preocupação major e minor) não correspondem a designações habitualmente utilizadas no contexto português, ainda que não tenha sido apontada uma designação alternativa. Foi ainda sugerido que se introduzissem itens que permitissem a identificação de aspectos positivos do funcionamento parental, a que os participantes se referiram como "forças" (Tabela 4, exemplo 8). Com menor frequência, foi sugerido que se fizessem duas correções na terminologia utilizada, nomeadamente a alteração de "guarda" para "exercício das responsabilidades parentais" e a referência a "prestadores de cuidados" em vez de "pai" e "mãe", dado que o Guia pode servir para avaliar outros cuidadores que não os pais biológicos. As alterações estruturais prendem-se com o posicionamento de alguns itens, bem como as condições da sua utilização (Tabela 4, exemplo 9).

Quanto às alterações em termos de metodologia de utilização foram sugeridas duas. Os académicos propuseram que se venha a definir o peso relativo das diferentes dimensões para a tomada de decisão (Tabela 4, exemplo 10), uma vez que consideraram que os diferentes conteúdos não têm a mesma importância. Os magistrados sugeriram a possibilidade de a aplicação do Guia ser proporcional à especificidade de cada caso, não sendo obrigatória a aplicação de todo o instrumento em todos os casos a avaliar (Tabela 4, exemplo 11).

\section{Exequibilidade da Aplicação do Guia}

Os técnicos consideraram que as tarefas inerentes à utilização do Guia são exequíveis nas atuais condições de funcionamento das instituições que trabalham na área da proteção à infância, tendo em conta a existência de equipas técnicas que podem ser formadas para a utilização desse instrumento. Refira-se que tanto os técnicos (Tabela 4, exemplo 12) como os magistrados enfatizaram a importância dessa formação.

\section{Utilidade dos Pareceres Produzidos a partir da Informação Recolhida}

Para responder a essa questão, os magistrados usaram como referência o relatório exemplo que lhes havia sido enviado. Foi destacada a pertinência e fundamentação da informação produzida, referindo a importância, para os magistrados, de compreenderem o processo que leva os técnicos a formularem determinados prognósticos, relativamente à criança e aos seus cuidadores, e a proporem determinadas medidas. Os magistrados salientaram que é necessário apontar factos (Tabela 4, exemplos 13 e 14) e apresentar a avaliação que é feita das suas implicações e do seu significado; consideraram que esses elementos estavam presentes no relatório apresentado, sendo que nem sempre lhes é necessária toda a informação que o Guia contém, devendo essa seleção ser feita e fundamentada pelo técnico em função das características específicas de cada caso.

\section{Atualidade Científica do Guia}

Os académicos consideraram que o Guia reflete o conhecimento científico atual relativamente às áreas avaliadas (Tabela 4, exemplo 15). Salientaram, no entanto, que não está clara a forma como se pondera a informação recolhida para a classificação da mesma nas quatro categorias (força major e minor, preocupação major e minor), com base nas quais se define depois um perfil da capacidade parental. Pela sua relevância, consideram que tal deve ser devidamente clarificado, nomeadamente em termos das implicações desta ponderação para as metodologias de intervenção a desenvolver e para as medidas de promoção e proteção a propor.

\section{Conclusões}

Perante os dados obtidos, considera-se que o Guia de Avaliação das Capacidades Parentais (De Rancourt et al., 2006) assenta em conhecimento científico atualizado (nas áreas da avaliação, da parentalidade e da intervenção em matéria de proteção à infância) e possibilita a obtenção de informação suficiente para este tipo de avaliação. Esta, sendo analisada segundo critérios claros, que reflitam o conhecimento científico atual e que estejam associados às implicações futuras das decisões a tomar, permitirá a fundamentação adequada dos pareceres técnicos e das decisões judiciais que dela advenham. Acresce que as tarefas inerentes à sua utilização foram consideradas exequíveis. Ainda assim, e para que a relação com o contexto português seja maximizada, deverão ser incluídas no instrumento um conjunto de alterações: 1) a nível do conteúdo deverão: i) ser definidos os critérios de decisão relativos à classificação das nove dimensões do Guia nas categorias força ou preocupação, major ou minor; ii) alterada a designação dessas categorias, propondo as autoras as designações de recurso principal ou secundário e dificuldade principal ou secundária; iii) introduzidos itens que permitam a identificação de aspectos positivos do funcionamento parental; e iv) substituídas as designações de "guarda" por "responsabilidades parentais" e de "pai ou mãe" por "prestador de cuidados"; 2) a nível estrutural deverá incluir-se no início do Guia a referência às condições de utilização do mesmo; 3) a nível metodológico, deverá ser clarificado: i) o peso relativo das diferentes 
dimensões para a tomada de decisão final sobre as duas hipóteses de evolução que o profissional considera que a(s) figura(s) parental(ais) avaliada(s) apresenta(m) - potencial de mudança encorajador ou alto risco de cronicidade - ; e ii) explorada a possibilidade de aplicação parcelar do Guia, proporcional à especificidade de cada caso.

Deverá ainda ser garantida formação aos profissionais que viabilize uma correta aplicação, quer em termos do processo de recolha e análise da informação, quer da transmissão e utilização dos seus resultados em matéria de proteção à infância.

O tamanho reduzido da amostra, em cada um dos grupos focais, constitui uma limitação que não deve ser ignorada, ainda que os mesmos tenham integrado, como foi realçado, elementos com muita experiência e reconhecido mérito no contexto nacional e a informação tenha, nos tópicos em avaliação, atingido um nível de saturação intra-grupo que não faz antever posições divergentes relevantes decorrentes do alargamento da mesma. Pelo facto de terem sido reportados alguns pontos de vista distintos, nomeadamente por parte dos magistrados e no que diz respeito à utilização integral ou proporcional do Guia, consoante as situações a avaliar, seria pertinente realizar este estudo no seio de grupos focais heterogéneos, que incluíssem profissionais das diferentes áreas, para melhor ponderar esta questão.

Os resultados deste estudo informaram as fases subsequentes dos estudos exploratórios de validação do Guia de Avaliação das Capacidades Parentais (fiabilidade e validade preditiva) para o contexto português (Pereira, 2014).

\section{Referências}

Araújo, D., Davids, K., \& Passos, P. (2007). Ecological validity, representative design, and correspondence between experimental task constraints and behavioral setting: Comment on Rogers, Kadar, and Costall (2005). Ecological Psychology, 19(1), 69-78. doi:10.1080/10407410709336951

Barudy, J., \& Dantagnan, M. (2010). Los desafios invisibles de ser madre o padre. Manual de evaluación de las competencias y la resiliencia parental. Barcelona: Gedisa.

Belsky, J., \& Vondra, J. (1989). Lessons from child abuse: The determinants of parenting. In D. Cicchetti \& V. Carlson (Eds.), Child maltreatment: Theory and research on the causes and consequences of child abuse and neglect (pp. 153-202). New York: Cambridge University Press.

Bowden, C. (2009, March). Parenting capacity assessments: A psychologist perspective. Comunicação apresentada na Child Protection Conference, British Columbia.

Çakir, M. (2012). Epistemological dialogue of validity: Building validity in educational and social research. Education, 132(3), 664-674.

Choate, P. W., \& Engstrom, S. (2014). The “Good Enough" Parent: Implications for Child Protection. Child Care in Practice, 20(4), 368-382. doi: 10.1080/13575279.2014.915794

Comissão Nacional de Proteção de Crianças e Jovens em Risco (2011). Guia de orientações para os profissionais da ação social na abordagem de situações de maus tratos ou outras situações de perigo. Retrieved from http://www.cnpcjr.pt/ downloads/Guia_accao_social.pdf
Department of Health, Department for Education and Employment \&Home Office (2000). The Framework for the Assessment of Children in Need and their Families (reference:DH-4014430). London: Her Majesty's Stationery Office. Retrieved from https:// www.education.gov.uk/publications/eOrderingDownload/ Framework $\% 20$ for $\% 20$ the $\% 20$ assessment $\% 20$ of $\% 20$ children $\% 20$ in $\% 20$ need $\% 20$ and $\% 20$ their $\% 20$ families.pdf

De Rancourt, L., Paquette, F., Paquette, D., \& Rainville, S. (2006) Guide d'évaluation des capacités parentales: Adaptation du guide de Steinhauer: 0 à 5 ans (3éd.). Montréal: Centres Jeunesse de Montréal.

Family Disability Studies Initiative (2012). Parenting Capacity Assessments: Some Guiding Principles. (Practice Points). Retrieved from http://www.fdsa.ualberta.ca/AboutUs/Sup portingParentswithIntellectualDisabilities/PracticePoints/ Capacity.aspx.

Gillingham, P., \& Humphreys, C. (2010). Child protection practitioners and decision-making tools: Observations and reflections from the front line. British Journal of Social Work 40(8), 2598-2616.doi:10.1093/bjsw/bcp 155

Hammond, K. R. (1998). Ecological validity: Then and now. Retrieved from http://www.brunswik.org/notes/essay2.html.

King, J. E. (2004, February). Software Solutions for Obtaining a Kappa-Type Statistic for Use with Multiple Raters. Paper presented at the Annual Meeting of the Southwest Educational Research Association, Dallas.

LaRossa, R. (2005). Grounded theory methods and qualitative family research. Journal of Marriage and Family, 67(4), 837857.doi: 10.1111/j.1741-3737.2005.00179.x

Lombard, M., Snyder-Duch, J., \& Bracken, C. C. (2010). Practical resources for assessing and reporting intercoder reliability in content analysis Research Projects. Retrieved from http:// www.temple.edu/sct/mmc/reliability/

Munro, E. (2008). Effective child protection (2nd ed.). London: Sage Publications.

Paquette, F. (2004). À chaque enfant son projet de vie permanent: Un programme d'intervention. Montréal: Centres Jeunesse de Montréal - Institut Universitaire.

Pereira, D. (2014). Parentalidade e proteção à infância: um guia para a avaliação da capacidade parental. (Unpublished doctoral dissertation). Universidade de Coimbra, Coimbra.

Robin, P. (2011). L'évaluation de la maltraitance en tension: L'exemple de la définition participative d'un référentiel. In C. Gaux \& I. Vinatier (Eds.), Outils pour la formation, l'éducation et la prévention: Contributions de la psychologie et des sciences de l'éducation: actes du colloque OUFOREP, 6-7 Juin 2011: Vol.3. Modes d'élaboration et de validation des outils et dispositifs pour la formation, l'éducation et la prévention, (pp. 219-228). Nantes: Outils pour la formation, l'éducation et la prévention.

Rossello, J., \& Bernal, G. (1996). Adapting cognitive-behavioral and interpersonal treatments for depressed Puerto Rican adolescents. In E. D. Hibbs \& P. S. Jensen (Eds.), Psychosocial treatments for child and adolescent disorders: Empirically based strategies for clinical practice (pp. 157-185). New York: American Psychological Association.

Schmuckler, M. A. (2001). What is ecological validity? A dimensional analysis. Infancy, 2(4), 419-436. doi: 10.1207/ S15327078IN0204_02 
Service de Protection de la Jeunesse (2008). Référentiel d'évaluation du danger encouru par l'enfant et des compétences parentales (Doc n ${ }^{\circ}$ R3.20). Canton de Vaud: Département de la formation, de la jeunesse et de la culture - Service de protection de la jeunesse.

Steinhauer, P. (1993). Assessing parenting capacity. Newsletter of the Infant Mental Health Promotion Project, 8, 5-7.
Tippins, T. M., \& Wittmann, J. P. (2005). Empirical and ethical problems with custody recommendations: A Call for Clinical Humility and Judicial Vigilance. Family Court Review, 43(2), 193-222. doi: 10.1111/j.1744-1617.2005.00019.x

White, A. (2005). Assessment of parenting capacity: Literature review. Ashfield: NSW Department of Community Services: Centre for Parenting \& Research. 